\title{
The pro-oncogenic effect of the IncRNA H19 in the development of chronic inflammation-mediated hepatocellular carcinoma
}

\author{
Lika Gamaev $^{1} \cdot$ Lina Mizrahi $^{1} \cdot$ Tomer Friehmann ${ }^{1} \cdot$ Nofar Rosenberg $^{1} \cdot$ Orit Pappo $^{2} \cdot$ Devorah Olam $^{1}$. \\ Evelyne Zeira ${ }^{1} \cdot$ Keren Bahar Halpern, ${ }^{3} \cdot$ Stefano Caruso $^{4} \cdot$ Jessica Zucman-Rossi $\mathbb{D}^{4,5} \cdot$ Jonathan H. Axelrod ${ }^{1}$. \\ Eithan Galun ${ }^{1} \cdot$ Daniel S. Goldenberg (1) ${ }^{1}$
}

Received: 4 June 2020 / Revised: 1 October 2020 / Accepted: 5 October 2020 / Published online: 22 October 2020

(c) The Author(s), under exclusive licence to Springer Nature Limited 2020

\begin{abstract}
The oncofetal long noncoding RNA (IncRNA) H19 is postnatally repressed in most tissues, and re-expressed in many cancers, including hepatocellular carcinoma (HCC). The role of $H 19$ in carcinogenesis is a subject of controversy. We aimed to examine the role of $H 19$ in chronic inflammation-mediated hepatocarcinogenesis using the $M d r 2 / A b c b 4$ knockout $(M d r 2$ $K O)$ mouse, a well-established HCC model. For this goal, we have generated $M d r 2-K O / H 19-K O$ double knockout $(d K O)$ mice and followed spontaneous tumor development in the $d K O$ and control $M d r 2-K O$ mice. Cellular localization of $H 19$ and effects of $H 19$ loss in the liver were determined in young and old $M d r 2-\mathrm{KO}$ mice. Tumor incidence and tumor load were both significantly decreased in the liver of $d K O$ versus $M d r 2-K O$ females. The expression levels of $H 19$ and $I g f 2$ were variable in nontumor liver tissues of $M d r 2-K O$ females and were significantly downregulated in most matched tumors. In nontumor liver tissue of aged $\mathrm{Mdr2}-\mathrm{KO}$ females, $\mathrm{H} 19$ was expressed mainly in hepatocytes, and hepatocyte proliferation was increased compared to $d K O$ females. At an early age, $d K O$ females displayed lower levels of liver injury and B-cell infiltration, with higher percentage of binuclear hepatocytes. In human samples, $H 19$ expression was higher in females, positively correlated with cirrhosis (in nontumor liver samples) and negatively correlated with CTNNB1 (beta-catenin) mutations and patients' survival (in tumors). Our data demonstrate that the lncRNA H19 is pro-oncogenic during the development of chronic inflammation-mediated HCC in the $M d r 2-K O$ mouse model, mainly by increasing liver injury and decreasing hepatocyte polyploidy in young mice.
\end{abstract}

Supplementary information The online version of this article (https:// doi.org/10.1038/s41388-020-01513-7) contains supplementary material, which is available to authorized users.

Daniel S. Goldenberg

goldenberg@ hadassah.org.il

1 The Goldyne Savad Institute of Gene and Cell Therapy, HadassahHebrew University Medical Center, Jerusalem, Israel

2 Department of Pathology, Hadassah-Hebrew University Medical Center, Jerusalem, Israel

3 Department of Molecular Cell Biology, Weizmann Institute of Science, Rehovot, Israel

4 Centre de Recherche des Cordeliers, INSERM, Sorbonne Université, Université de Paris, Functional Genomics of Solid Tumors Laboratory, F-75006 Paris, France

5 Hôpital Européen Georges Pompidou, AP-HP, F-75015 Paris, France

\section{Introduction}

Hepatocellular carcinoma (HCC) is the most prevalent primary liver cancer and is the 3rd leading cause of cancerrelated death worldwide [1]. Despite significant progress in our understanding of the risk factors for HCC development, there are still major unmet needs in HCC early diagnosis, prevention, and therapy [1]. The role of the long noncoding RNA (lncRNA) $\mathrm{H} 19$ in the pathogenesis of $\mathrm{HCC}$ is a debatable issue [2]. H19 is paternally imprinted and maternally expressed; it is widely expressed in the embryo, but is repressed at birth in most tissues, and is re-expressed in many cancer types, including HCC. Some studies demonstrated a tumor-suppressive role for H19 in HCC development [3], whereas other studies revealed its oncogenic role [4]. However, none of these studies used an HCC model in which tumor development was preceded by chronic liver inflammation, as it happens in most human cases [1]. Thus, we aimed to examine the role of H19 in 
chronic inflammation-mediated hepatocarcinogenesis and to elucidate the associated molecular mechanisms. For this goal, we used the $M d r 2$ knockout $(M d r 2-K O)$ mouse, a well-established model of chronic cholangitis and hepatitis, which culminate in HCC development, mimicking these processes in HCC patients [5-8]. In order to elucidate the effect of $H 19$ on hepatocarcinogenesis in chronically inflamed liver, we generated the $\mathrm{Mdr2-KO/H19-KO}$ double knockout $(d K O)$ mice by transferring the $H 19 \Delta 3$ mutation (a 3-kb deletion of the $H 19$ encoding region [3]) from the $129 \mathrm{~Sv}$ to the C57BL/6 (B6) $M d r 2-K O$ strain, and followed the development of spontaneous tumors in the $d K O$ and the parental Mdr2-KO mice. Previously, we found that $H 19$ expression in the nontumor liver of adult $\mathrm{Mdr2-KO}$ mice was much higher in females than in males [9]. Thus, in the current study we focused mainly on the role of $\mathrm{H} 19$ in HCC development in female $M d r 2-K O$ mice.

\section{Results}

\section{Loss of H19 impedes tumor development in the liver of Mdr2-KO mice}

Comparison of aged $d K O$ with age- and sex-matched $M d r 2$ $K O$ controls demonstrated that $d K O$ females had significantly decreased tumor incidence (Fig. 1A) and tumor load (Fig. 1B), and a tendency to reduced average tumor size (Fig. 1C), while in $d K O$ males, only tumor load was significantly decreased (Supplementary Fig. 1C). Loss of $\mathrm{H} 19$ also resulted in a significantly reduced liver-to-body weight index (LBI) in both $d K O$ females (Fig. 1D) and males (Supplementary Fig. 1D). Proliferation intensity of hepatocytes was significantly reduced in $d K O$ versus $M d r 2$ $K O$ females (Fig. 1E and Supplementary Fig. 2). For both genders, there was no significant difference in animal weights between groups (data not shown) and in the ALT and ALP serum levels that serve as indicators of hepatocyte and cholangiocytes injury, respectively (Fig. 1F and Supplementary Fig. 1E). Taken together these results demonstrate reduced hepatocarcinogenesis in $M d r 2-K O$ mice upon deletion of $H 19$.

\section{In the liver of Mdr2-KO mice, H19 is expressed mainly in nontumor hepatocytes}

Since Igf2 is a known oncogenic driver in HCC [10], and shares a transcriptional enhancer with $H 19$, we measured the levels of $H 19$ and $I g f 2$ transcripts in the liver of aged Mdr2-KO mice. Both $H 19$ and Igf2 expressions in the liver of $M d r 2-K O$ females were variable in the nontumor tissue, while hardly detectable in most tumors (Fig. 2A). There was no correlation between $H 19$ and $I g f 2$ expression either in the nontumor liver (Supplementary Fig. 3A), or in tumors (Supplementary Fig. 3B).

In order to determine which liver cell lineages express H19, we used single-molecule RNA-FISH (smRNA-FISH) technique combining H19-specific probe with either Pckl (hepatocyte-specific) or Krt19 (cholangiocyte-specific) probes. In aged Mdr2-KO females, $H 19$ was expressed in a small fraction of hepatocyte-shaped cells scattered in the liver without a significant zonation (Fig. 2B). The H19positive cells also expressed hepatocyte-specific Pckl transcript (Fig. 2C, D), but not cholangiocyte-specific Krt19 transcript (Supplementary Fig. 3C, D), whereas all cholangiocyte-shaped cells did not express H19. Specificity of the H19 probe was confirmed by the lack of its hybridization in the liver of $\mathrm{Mdr2-KO/H19-KO}$ mouse (Supplementary Fig. 3E, F). Single-cell transcriptomic analysis of the nontumor liver tissue from an aged $M d r 2-K O$ female (Fig. 2E) also demonstrated that $H 19$ was expressed mainly in hepatocytes, while minor $H 19$ expression was detected in endothelial cells and monocytes/macrophages (Fig. 2F). Thus, our data prove that in the nontumor liver of aged Mdr2-KO females, $H 19$ is expressed mainly in hepatocytes.

It was previously shown that $H 19$ expression in the rodent liver is associated with hepatocyte proliferation [11] and that $H 19$ level in the postnatal mouse liver drops significantly after the 15 th day [12]. To investigate the role of H19 in hepatocyte proliferation in our model, we assessed the co-expression of H19 with the Mki67 (Supplementary Fig. 4A, B) and Cdkn1a (p21Cip; Supplementary Fig. 4C) transcripts in the liver of 15-day-old Mdr2-KO females. In both cases, about $70 \%$ of hepatocytes were H19-positive (Supplementary Fig. 4D, E). About 17\% of hepatocytes were Mki67-positive (Supplementary Fig. 4D), and about $68 \%$ of hepatocytes were Cdknla-positive (Supplementary Fig. 4E), but for both markers, about $2 / 3$ of positive cells were positive also for $H 19$. Thus, we did not find any correlation between expression of H19 and Mki67 or $C d k n 1 a$ in hepatocytes of these mice. Also, quantitation of the p21Cip protein level in the liver of 3-month-old Mdr2$K O$ and $d K O$ females by immunoblotting and immunohistochemistry, revealed no difference between groups (data not shown).

\section{H19 loss decreases liver injury and increases the proportion of binuclear hepatocytes in the liver of young Mdr2-KO mice}

Comparison of $d K O$ with $M d r 2-K O$ females at the age of 3 months demonstrated that $d K O$ females had significantly reduced serum ALT and ALP levels (Fig. 3A), as well as reduced LBI (Fig. 3B). All these parameters in the $d K O$ mice were, on average, intermediate between the healthy $M d r 2+/-$ heterozygotes and chronically inflamed $M d r 2-K O$ 
Fig. 1 H19 loss impeded hepatocarcinogenesis in $M d r 2$ $\boldsymbol{K} \boldsymbol{O}$ females. Decreased tumor incidence (A, each dot represents the largest tumor per mouse, and its maximal diameter is shown on the axis " $Y$ "), and load (B), but not tumor size (C) in $M d r 2-K O / H 19-K O$ (black; $n=18$ ) versus $M d r 2-K O$ (white; $n=15)$ 16-month-old females. Reduced liver-to-body index (D) and percentage of Ki67-positive hepatocytes in nontumor liver tissue (E) in $\mathrm{Mdr2}-\mathrm{KO} / \mathrm{H} 19-\mathrm{KO}$ (black) versus $M d r 2-K O$ (white) 16-month-old females. F Similar ALT and ALP levels in the serum of both experimental groups. Mouse numbers in groups in $\mathbf{D}, \mathbf{F}$ - as in $\mathbf{A - C}$; in $\mathbf{E}$ $n=8$. Fisher exact test (A) or the two-tailed unpaired $t$-test (B-F). $p$ values: ${ }^{*} p<0.05$; $* * p<0.01 ; * * * p<0.001$; $* * * * p<0.0001$.
A
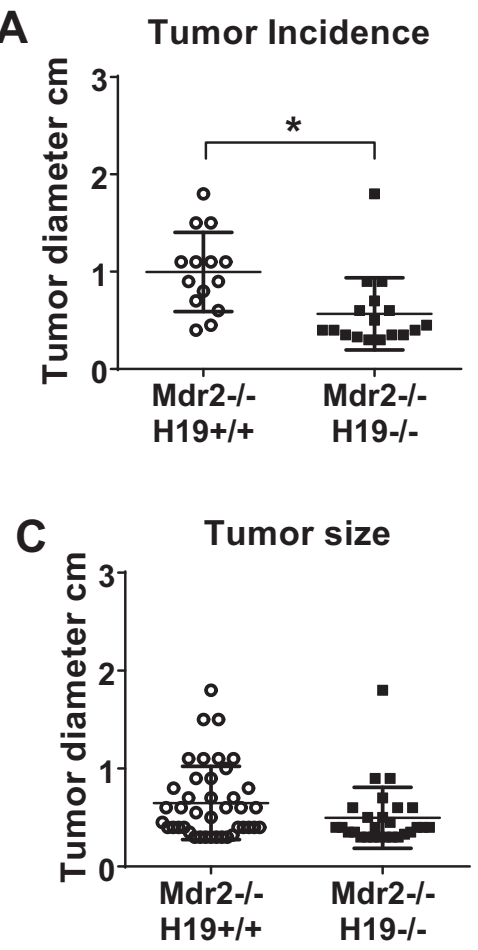

B
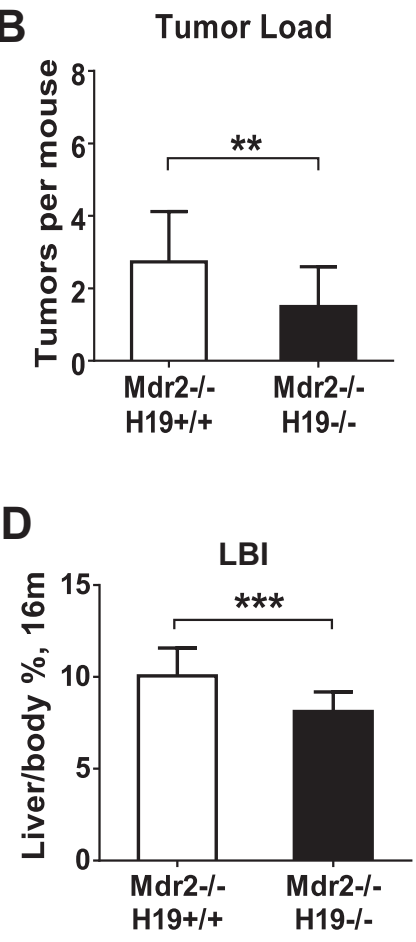

E

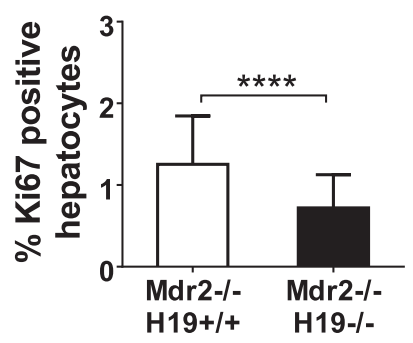

$\mathbf{F}$

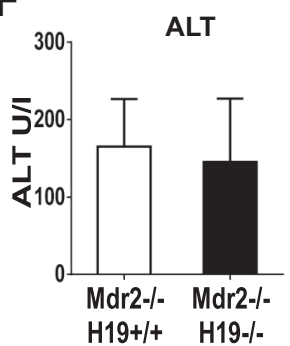

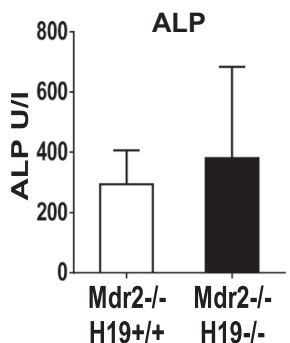

controls. Histologically, livers of 3-month-old $d K O$ females had reduced ductular reaction compared to $M d r 2-K O$ females (Fig. 3C). In search of a cause for the reduced liver injury in $d K O$ mice, we compared the numbers of immune cells in the liver of $d K O$ and $M d r 2-K O$ females. Immunohistochemical (IHC) staining for B220, a marker of B cells, revealed a significantly lower infiltration of B cells into the liver of $d K O$ compared to $M d r 2-K O$ females (Fig. 3D, E). However, IHC staining for F4/80, a marker of monocytes and macrophages, revealed no difference between groups (Fig. 3F). Previously, it was demonstrated that $H 19$ expression in primary hepatocytes was inversely correlated with cell polyploidization [13]. In accordance, our results revealed that the percentage of binuclear hepatocytes (that represent the main fraction of polyploid hepatocytes in rodent liver [14]) was significantly higher in the 3-month-old $d K O$ compared to $M d r 2-K O$ females (Fig. 4A, B). This difference between groups disappeared at the age of 16 months (data not shown). In addition, 3-month-old $d K O$ compared to $M d r 2-K O$ females had reduced numbers of
Ki67-positive hepatocytes (Fig. 4C and Supplementary Fig. 2). $H 19$ expression in the liver of $M d r 2-K O$ females was variable and significantly increasing with age (Fig. 4D compared to Fig. 2A).

\section{Decreased expression of genes associated with inflammation, apoptosis, and epithelial-mesenchimal transition in the livers of dKO versus Mdr2-KO females}

To explore molecular mechanisms associated with the effect of $H 19$ loss on HCC development at early and late stages of chronic inflammatory liver disease, we compared whole liver transcriptomes of $d K O$ versus $M d r 2-K O$ females aged either 3 or 16 months using RNA-seq technique. For old mice, total RNA was purified from nontumor liver counterparts. Gene Set Enrichment Analysis (GSEA) of the RNA-seq data revealed that at both analyzed ages, seven gene sets were enriched in the $M d r 2-K O$ compared to $d K O$ transcriptomes. These sets were mainly associated with 
Fig. 2 In the liver of old Mdr2$\mathrm{KO}$ females, $\mathrm{H} 19$ is expressed mainly in hepatocytes. A Expression of $\mathrm{H} 19$ and $\mathrm{Igf} 2$ transcripts in the nontumor (NT) and tumor (T) liver tissue of 16month-old B6 $M d r 2-K O$ females (qRT-PCR, normalized to Hprt expression). B-D Singlemolecule RNA-FISH (smRNAFISH) of $\mathrm{H} 19$ in murine liver. B Scattered location and small percentage of H19-positive hepatocytes in the liver of 15 month-old $M d r 2-K O$ female; $H 19$ (green) and Pckl (red). C Magnification of the liver region inside a rectangle frame in $\mathbf{B}$. The picture represents a snapshot of all layers. White arrows mark hepatocyte nucle positive for both $H 19$ (green) and Pck1 (red) signals. D SmRNA-FISH of $H 19$ (green) and $P c k l$ (red) in the liver of a 15-month-old $M d r 2-K O$ female. The picture represents a single layer. H19 is expressed only in hepatocytes (Pckl-positive cells with round nuclei), and not in cholangiocytes (Pckl-negative cells with prolonged nuclei). Scale bars: $10 \mu \mathrm{m}(\mathbf{B}, \mathbf{D})$, and $100 \mu \mathrm{m}$ (C). E, F Single-cell transcriptomic analysis of the nontumor liver tissue of 18 month-old B6 $M d r 2-K O$ female. E Cell clusters. F H19 expression (blue dots) in cell clusters shown in $\mathbf{E}$; relative expression scale (blue color intensity)—from 0 to 0.7 units. $p$ values designations - as in Fig. 1.

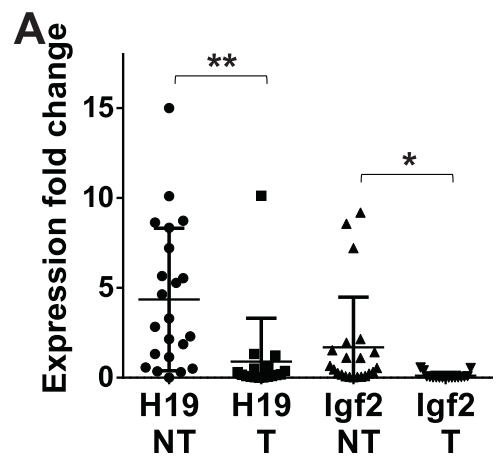

B

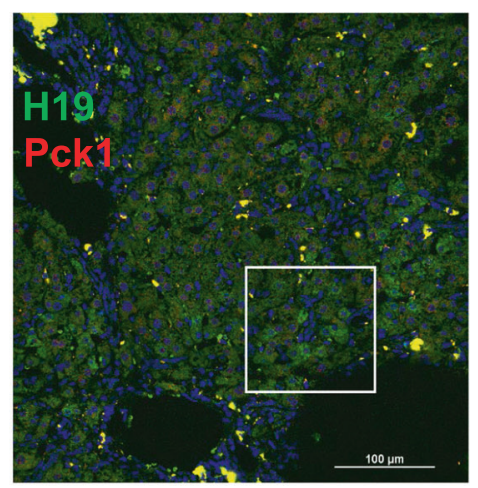

C

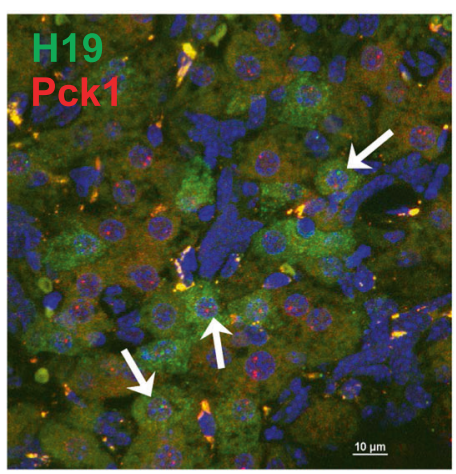

D

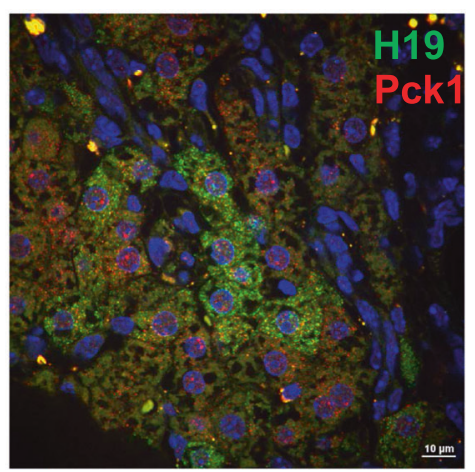

E

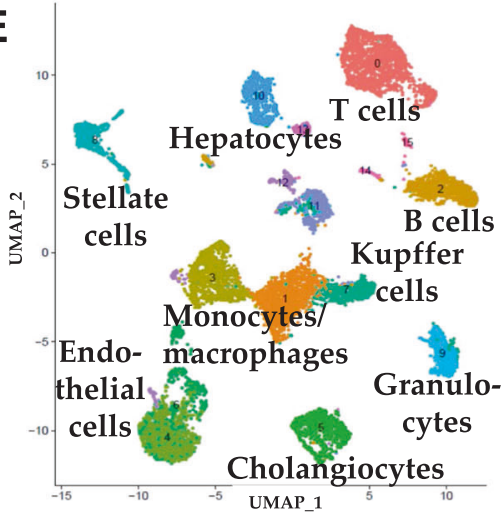

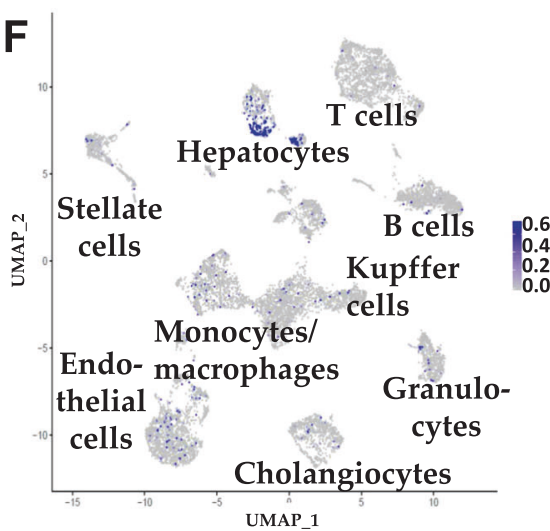

inflammatory and interferon responses, $\mathrm{TNF} \alpha$ signaling via $\mathrm{NFKB}$ and epithelial-mesenchymal transition (Fig. 5A and Supplementary Table 1). Individual genes differentially expressed between both genotypes are shown in Supplementary Table 2 (for 3-month-old females) and Supplementary Table 3 (for 16-month-old females). We have confirmed differential expression of selected genes by qRTPCR (Fig. 5B, C). In 3-month-old mice, we confirmed upregulation of the pro-inflammatory genes S100a8, S100a9, Ly6c1, Orm2, Ptprc (encoding B cells' marker B220), and Ccl21a (encoding a chemoattractant for B cells) in $M d r 2-K O$ females, and upregulation of the genes glucocorticoid-induced leucine zipper (Gilz/Tsc22d3), Tcim, Foxol, and NrOb2/Shp in $d K O$ females (Fig. 5B). In 16-month-old mice, we confirmed upregulation of genes dual specificity phosphatase 1 (Dusp 1) and growth arrest and DNA damage 45G (Gadd45g) in $d K O$ females (Fig. 5C).

\section{H19 expression pattern in human nontumor and tumor HCC samples is similar to that in Mdr2-KO model}

In an effort to determine the relevance of the mouse results to those of humans, we analyzed H19 expression levels in 298 adjacent nontumor counterparts (FNT), of HCC tumors of 55 women and 243 men (Supplementary Table 4). Similar to our finding in mice, $H 19$ expression in human nontumor liver samples was significantly higher in women compared to men (Fig. 6A). The expression of $\mathrm{H} 19$ was 
Fig. $3 \mathrm{H} 19$ loss reduces liver injury and B-cell infiltration into the liver of 3-month-old Mdr2-KO females. A Decreased ALT and ALP levels in the serum of $\mathrm{Mdr2-KO/H19-KO}$ (black, $n=14$ ) versus $M d r 2-K O$ (white, $n=19$ ) females; Mdr2 $+/-$ controls (gray, $n=4$ ). B Decreased liver-to-body weight index of $\mathrm{Mdr2}-\mathrm{KO} / \mathrm{H} 19-\mathrm{KO}$ versus $M d r 2-K O$ females; mice numbers and column colors-as in A. C Decreased ductular reaction in $\mathrm{Mdr2}-\mathrm{KO} / \mathrm{H} 19-\mathrm{KO}$ versus $M d r 2-K O$ females $(\mathrm{H} \& \mathrm{E}$ staining; magnification $\times 100$ ). D, E Significantly decreased level of B220-positive cells in Mdr2-KO/H19-KO mice. D Immunohistochemistry for B220; magnification $\times 200$. E Quantitation of the B220positive cells $(n=10 ; 5-720 x$ HPFs per mouse). F Similar levels of F4/80 expression in the liver of $M d r 2-K O / H 19-K O$ and $M d r 2-K O$ females (quantitation of immunohistochemistry for F4/80; numbers of mice and HPFs - as in E). $p$ values designations-as in Fig. 1.
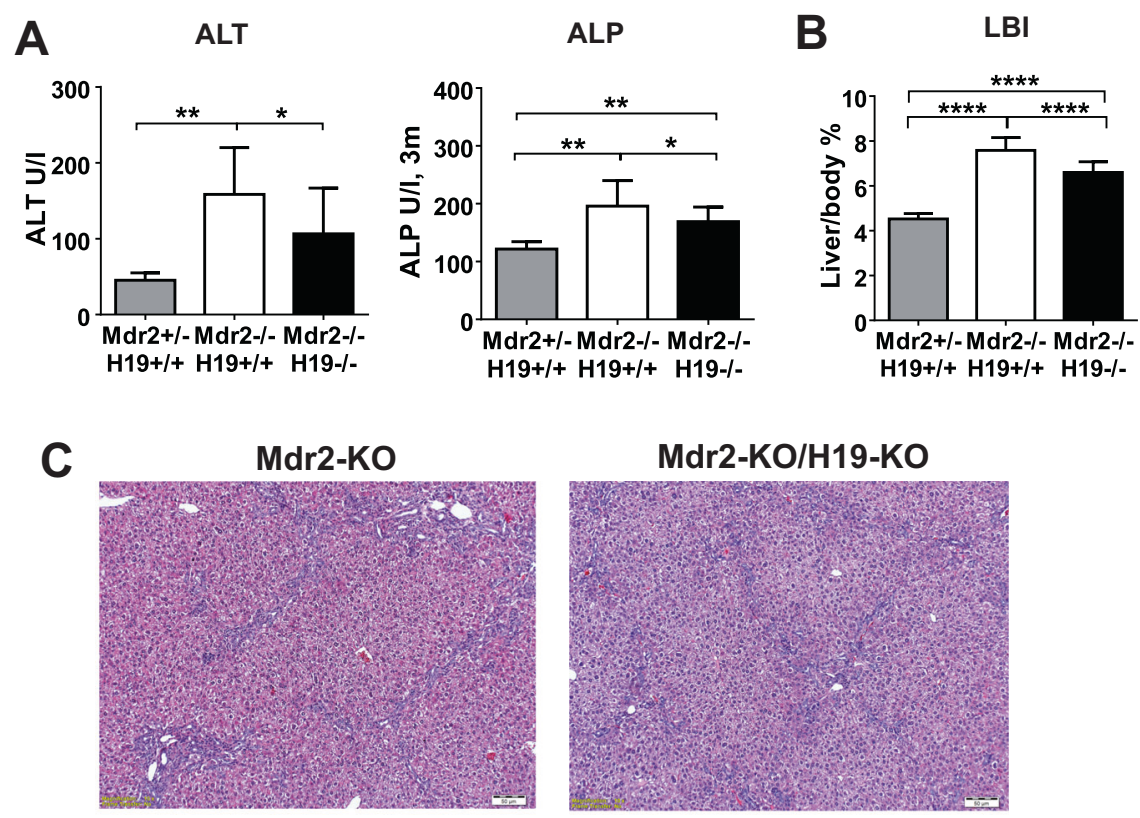

D
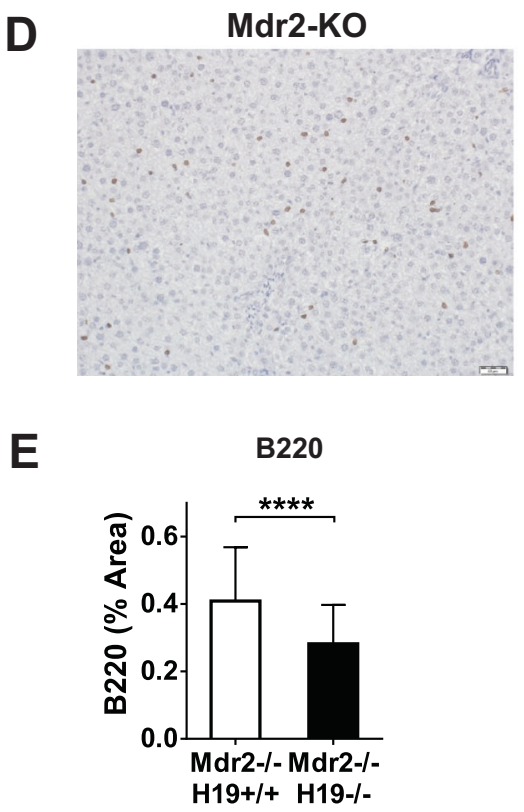
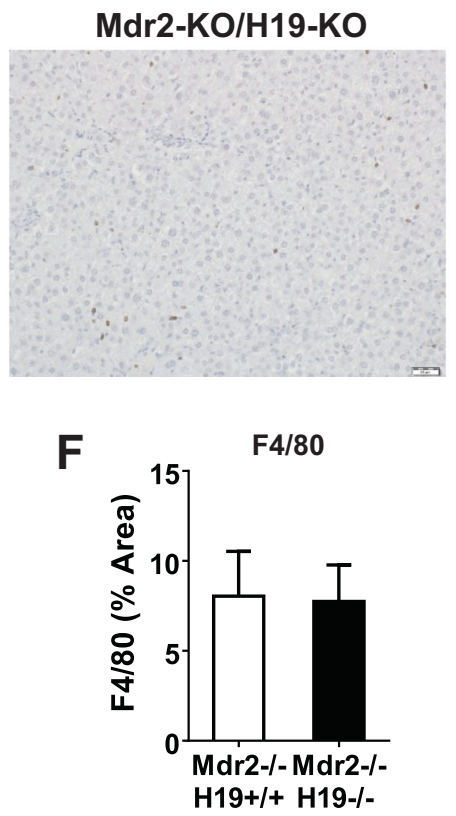

significantly associated with hepatitis $\mathrm{C}$ virus (HCV) infection in both men and women (Fig. 6B). There was a significant association of $H 19$ expression level with fibrosis stage (Fig. 6C) and cirrhosis (Fig. 6D) in males, while there was only a trend toward significance in females (Fig. 6C, D), probably due to the small sample size. Remarkably, in multivariate analysis, gender and cirrhosis were still significantly associated with $H 19$ expression, while HCV was no longer significant (Fig. 6E). These results could be explained by previous findings that $\mathrm{HCV}$ is significantly associated with cirrhosis. In both genders, H19 expression was significantly correlated with IGF2 expression (Fig. 6F).
Previously, using microarrays, we demonstrated that H19-overexpressing HCC tumors were present mainly in the "proliferative" subgroup G1 that contained mainly female samples and was associated with the absence of CTNNB1 mutations [15]. Here, we have confirmed these data by direct $H 19$ measurements of a larger number of tumor samples. $H 19$ was highly expressed mainly in the subgroup G1 (Fig. 7A); its expression in tumors significantly correlated with the IGF2 expression (Fig. 7B). Similar to nontumor samples, H19 expression in tumors was significantly higher in females (Fig. 7C). Remarkably, there was a significant negative correlation between the level of 

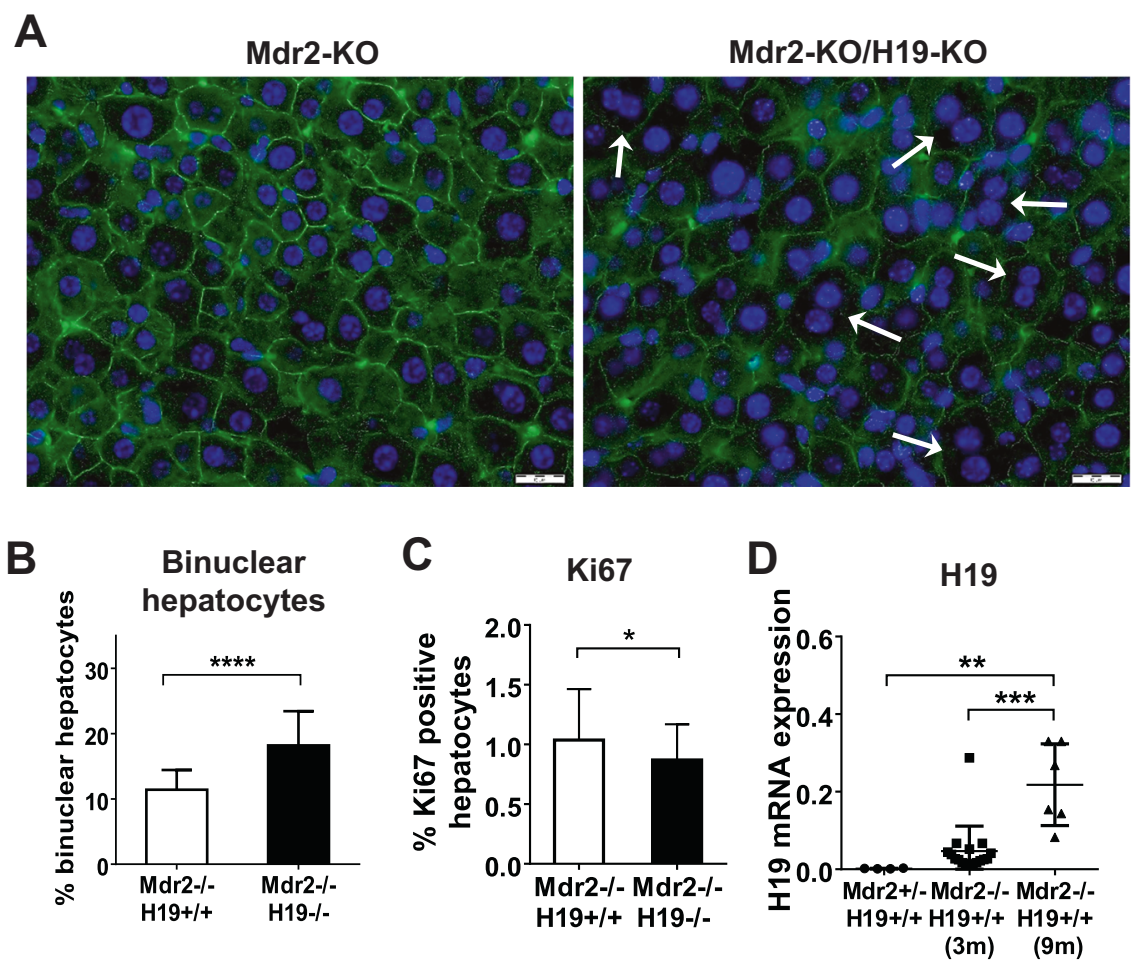

Fig. $4 \mathrm{H} 19$ loss increases proportion of binuclear hepatocytes in the liver of 3-month-old $M d r 2-K O$ females. A, B Increased number of binuclear hepatocytes (marked by white arrows) in the liver of Mdr2-KO/H19-KO versus $M d r 2-K O$ females. A Representative images of liver sections stained for $\beta$-catenin (green) to mark cell walls; magnification $\times 400$. B Quantitation of the images shown in $\mathbf{A} ; M d r 2$ KO/H19-KO (black) versus $M d r 2-K O$ (white) females (5-6 mice per

$H 19$ expression and the presence of CTNNB1 mutations in tumors (Fig. 7D). The level of $H 19$ expression in the tested HCC tumors had a tendency, at the limit of significance, to affect patient's survival in our dataset (Fig. 7E and Supplementary Table 5), but in the TCGA dataset, there was only a trend, without statistical significance (Supplementary Fig. 5).

\section{Discussion}

The role of lncRNA H19 in carcinogenesis, including hepatocarcinogenesis, is highly controversial: multiple studies support either its oncogenic or tumor-suppressive activity $[2,16]$. We decided to use the $M d r 2-K O$ mouse HCC model to explore the role of $H 19$ in HCC development for two main reasons: (1) none of the previous H19 studies used an HCC rodent model in which tumor development was preceded by chronic liver inflammation, which is typical for human HCC [1]; and (2) we have previously discovered that $\mathrm{H} 19$ is expressed in the nontumor liver of adult $M d r 2-K O$ mice, and that its expression is much higher in females [9]. Later, our findings were independently group; 5-7 20x fields per mouse; $p<0.0001)$. C Decreased number of Ki67-positive hepatocytes in the liver of $M d r 2-K O / H 19-K O$ versus $M d r 2-K O$ females $(n=9)$. D $H 19$ level in the liver of $M d r 2-K O$ females at the age of 3 and 9 months (qRT-PCR normalized to Hprt mRNA level; $M d r 2+/-3$-month-old females served as controls). $p$ values designations - as in Fig. 1.

confirmed by others [17]. The group of L. Dandolo demonstrated tumor-suppressive effect of $\mathrm{H} 19$ in three different mouse cancer models, including HCC [3]. Our results demonstrate the opposite: namely, in the $M d r 2-K O$ HCC model, $H 19$ acts as an oncogene, especially in females, where its expression is higher (probably, due to the known activation of the $H 19$ expression by 17-betaestradiol and estrogen receptor [18]). There are two main differences between mouse HCC models used by us and by L. Dandolo's group: (1) their model was not inflammatory, but was based on the expression of a transgene containing both large and small SV40 T-antigens that inactivate p53 and $\mathrm{Rb}$ tumor suppressors; (2) they used not the $H 19 \Delta 3$ mutant, but a mutant with deletion of the enhancer common for both $H 19$ and Igf2 genes [3]. Taking into account that H19 may interact with p53 protein and interfere with its activity [19], the HCC model with inactivated p53 does not seem suitable for studying the role of $\mathrm{H} 19$ in hepatocarcinogenesis. Another study, also using the H19A3 mutants, demonstrated a tumor-suppressive effect of $\mathrm{H} 19$ on HCC development [20]. However, in this study, HCC was induced in mice by DEN injection, thus, this HCC model was not a chronic inflammation-mediated one. 
A

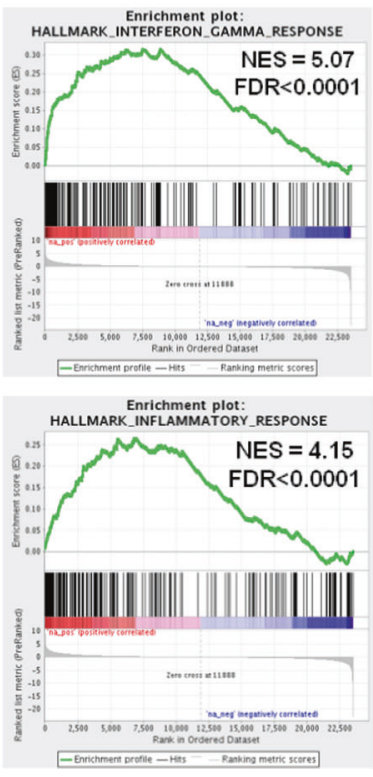

B
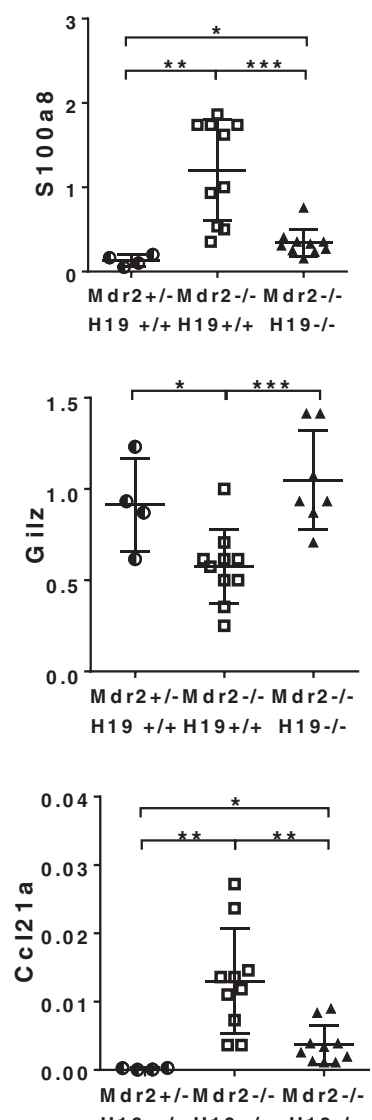
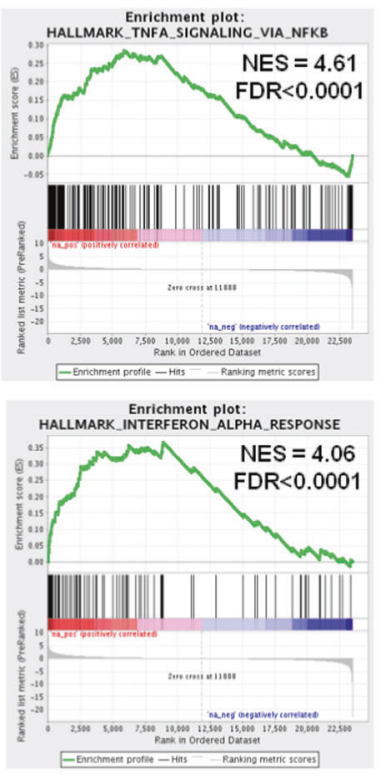

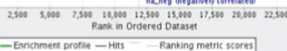

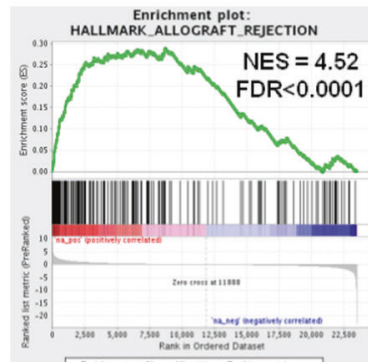

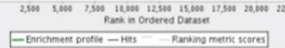

Enrichment plot:
HALLMARK_EPITHELIAL_MESENCHYMAL_TRANSITIO
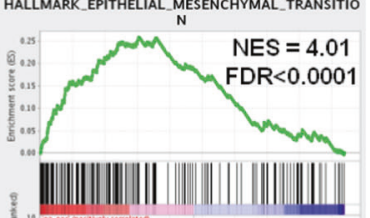

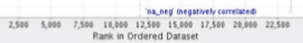

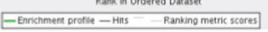
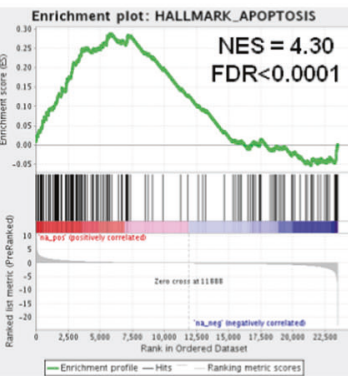

Enrichment plot:
HALUMARK OXIDATIVE PHOSPHORYLATION
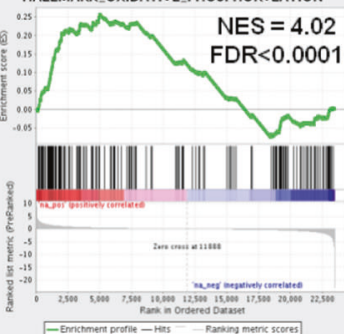

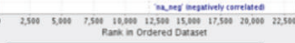
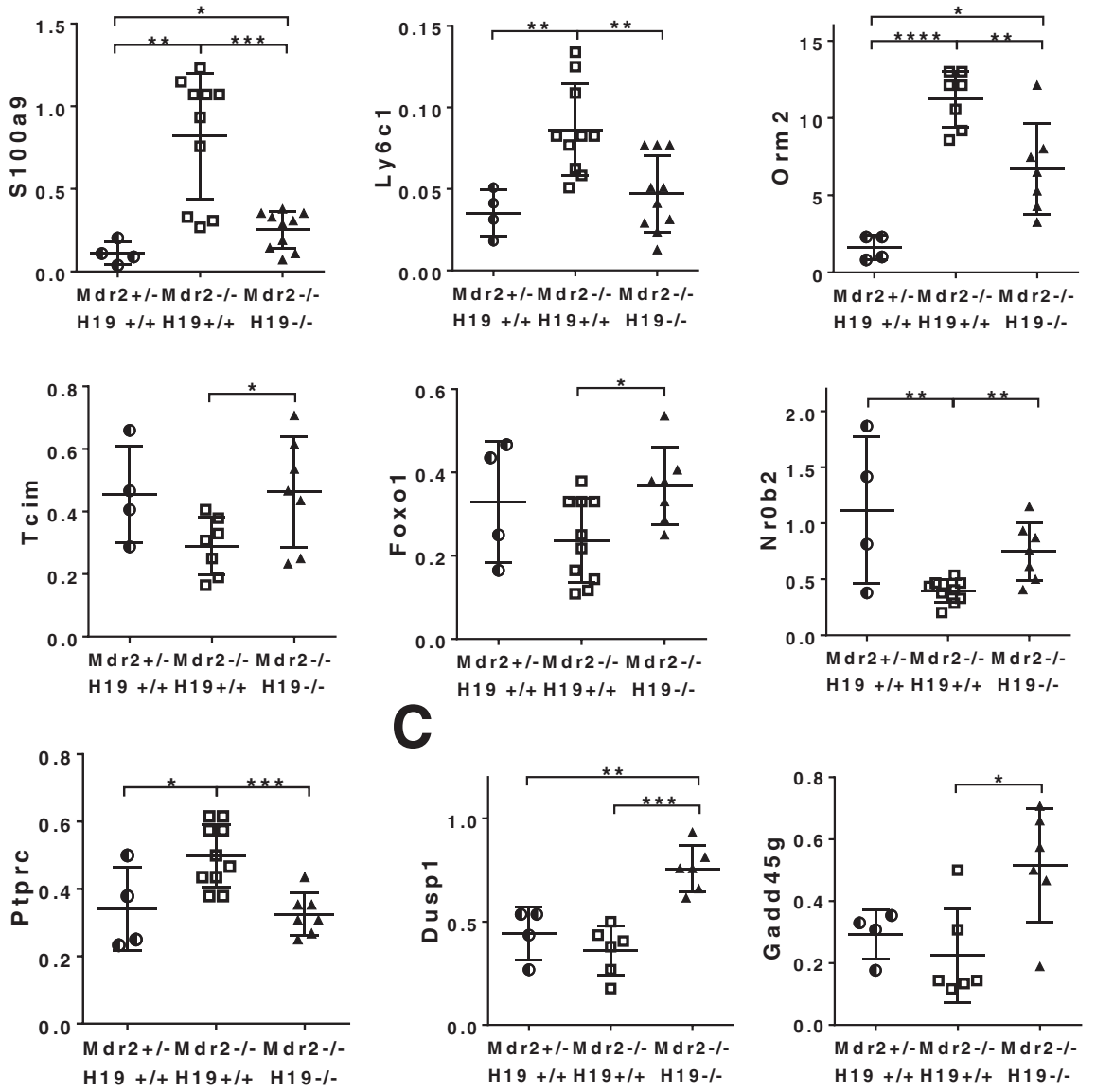
Fig. 5 Transcriptome profiling of livers from young and old $d K O$ versus $M d r 2-K O$ females using RNA sequencing and GSEA reveals decreased inflammation and liver injury in $d K O$ mice. A GSEAgenerated graphic plots representing the eight top gene sets that are enriched in the $M d r 2-K O$ versus $d K O$ liver transcriptomes in 3-monthold females. The first seven gene sets (excluding "oxidative phosphorylation") are also the top gene sets that are enriched in the $M d r 2$ $K O$ versus $d K O$ liver transcriptomes in 16-month-old females. B, C Confirmation by qRT-PCR of the results of RNA-seq analysis for individual genes that are differentially expressed in the livers of $M d r 2-$ $K O$ (empty squares) versus $d K O$ (black triangles) females aged either 3 months (B), or 16 months $(\mathbf{C})$. Seven to ten mice per group; four healthy age-matched $M d r 2+/-$ females used as controls (circles). $p$ values designations-as in Fig. 1 .
Fig. $6 \mathrm{H} 19$ expression in adjacent nontumor liver of HCC patients. A $\mathrm{H} 19$ expression in nontumor liver counterparts is significantly higher in women $(N=55)$ compared to men $(N=243)$ expression is significantly men (left) and women (right) (Wilcoxon test). C, D There is a significant association with fibrosis (C, Kruskal-Wallis test) and cirrhosis (D, Wilcoxon test) in men and a trend toward significance in women (probably, due to the small sample size). H19 expression values are represented with $\Delta \Delta \mathrm{Ct}$ method using $18 S R N A$ as calibrator and the five normal liver samples for relative expression. E Multivariate analysis demonstrated that gender and cirrhosis, but not $\mathrm{HCV}$, are significantly F Significant positive correlation between $H 19$ and $I G F 2$ expression in nontumor liver samples from both men and women (Spearman's correlation). (Wilcoxon test). B H19 associated with $\mathrm{HCV}$ in both associated with $H 19$ expression.
A

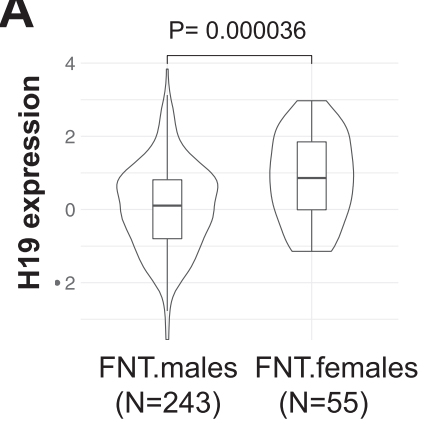

B

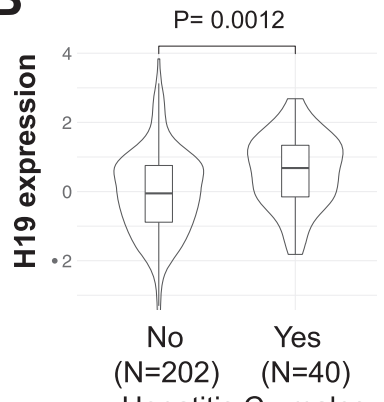

Hepatitis C, males

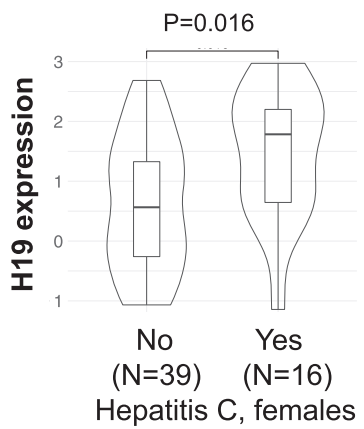

C

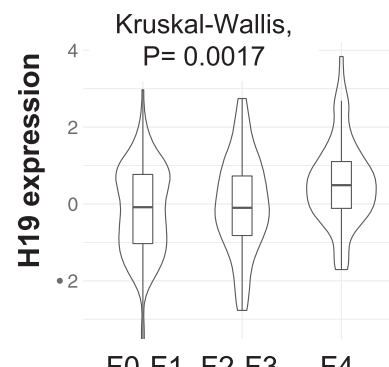

F0-F1 F2-F3 F4

$(\mathrm{N}=118)(\mathrm{N}=58)(\mathrm{N}=67)$

Fibrosis, males
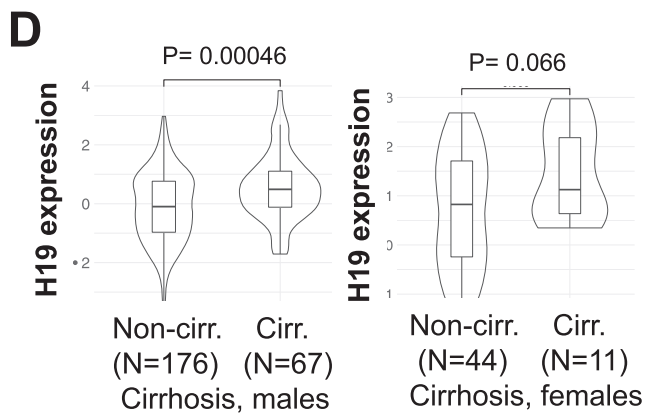

E

\section{Liver cells that express H19} mice is a controversial issue. The group of $\mathrm{H}$. Zhou found that in the liver of young $M d r 2-K O$ females, $H 19$ was expressed mainly in the cholangiocytes with minor expression in hepatocytes [17]. In contrast, the group of L. Wang demonstrated that in the liver of middle-aged $M d r 2$ KO females, H19 was expressed mainly in hepatocytes (with minor expression in Kupffer cells) [21]. In both these studies, the $M d r 2-K O$ mice were of the $\mathrm{FVB} / \mathrm{N}$ genetic
The type of liver cells that express H19 in the Mdr2-KO

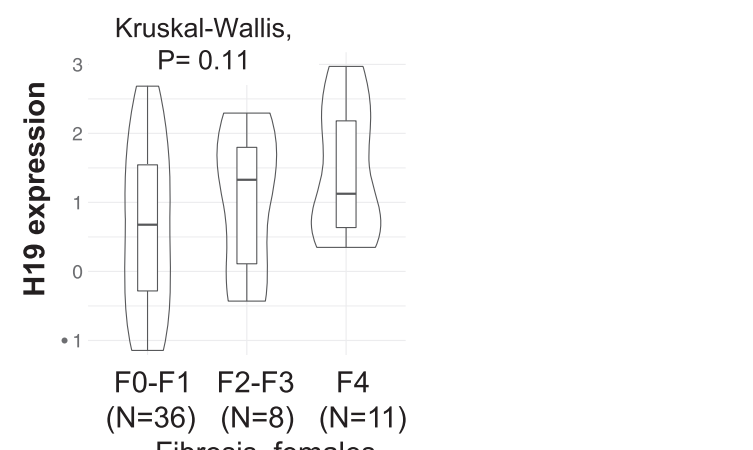

Fibrosis, females

Coefficients:
\begin{tabular}{|l|c|c|c|c|}
\hline & $\begin{array}{c}\text { Esti- } \\
\text { mate }\end{array}$ & $\begin{array}{c}\text { Std. } \\
\text { Error }\end{array}$ & $\mathrm{t}$ & $\mathrm{P}$ \\
\hline $\begin{array}{l}\text { Cirrhosis } \\
\text { (yes) }\end{array}$ & 0.688 & 0.219 & 3.139 & 0.00187 \\
\hline Gender (M) & -0.948 & 0.237 & $\mathbf{- 3 . 9 9 7}$ & $\mathbf{8 . 1 2 \mathrm { E } - 0 5}$ \\
$\begin{array}{l}\text { Hepatitis.C } \\
\text { (yes) }\end{array}$ & 0.475 & 0.248 & 1.916 & 0.05634 \\
***
\end{tabular}

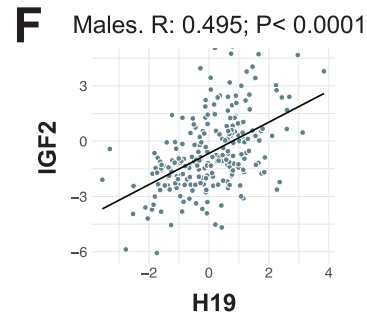

Females. R: $0.56 ; \mathrm{P}<0.0001$

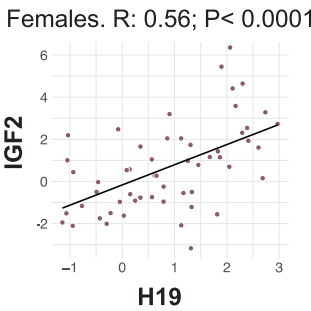


Fig. $7 \mathrm{H} 19$ expression in human HCC tumors. A $\mathrm{H} 19$ is highly expressed, mainly in the G1 ("proliferative") subgroup of HCC tumors (Kruskal-Wallis test for significance). B

Significant positive correlation between $\mathrm{H} 19$ and IGF2 expression in tumors (Spearman's correlation). C H19 expression in tumors is significantly higher in women $(N=45)$ compared to men $(N=$ 197) (Wilcoxon test). D $H 19$ expression in HCC tumors is significantly negatively correlated with mutations in the CTNNB1 gene encoding betacatenin (Wilcoxon test). E H19 expression in HCC tumors is a significant factor determining patient's survival (log-rank test). Patients were divided to two subgroups (119 patients in each subgroup) based on the median H19 expression in tumors (foldchange $\mathrm{T} / \mathrm{NT}=0.236$ ): " $\mathrm{H} 19$ low", $\mathrm{FC}<0.236$ and "H19 high", FC > 0.236.
A

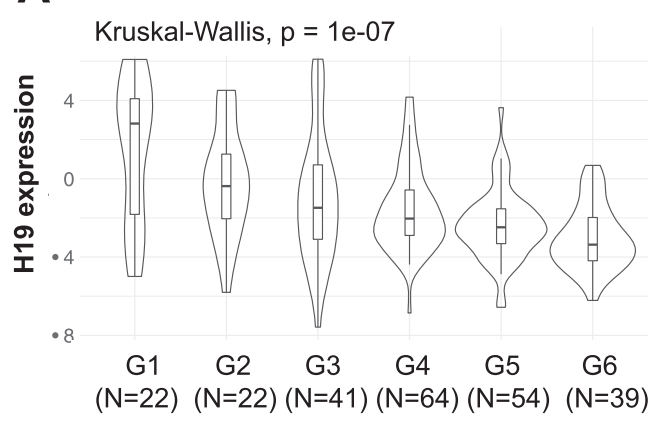

B

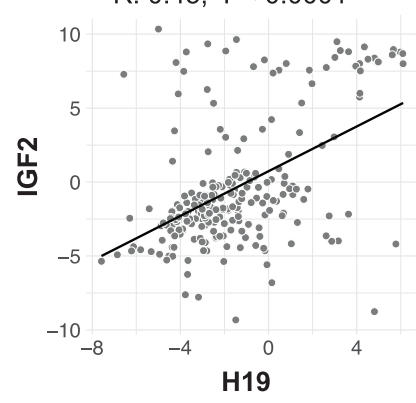

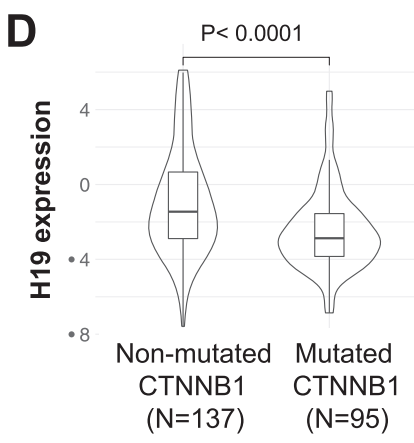

E

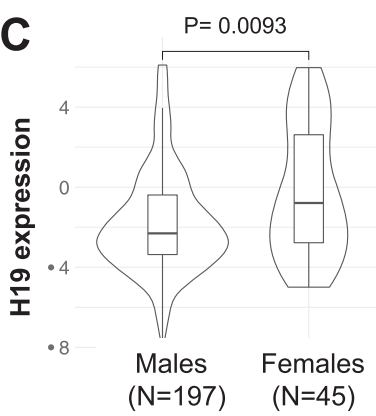

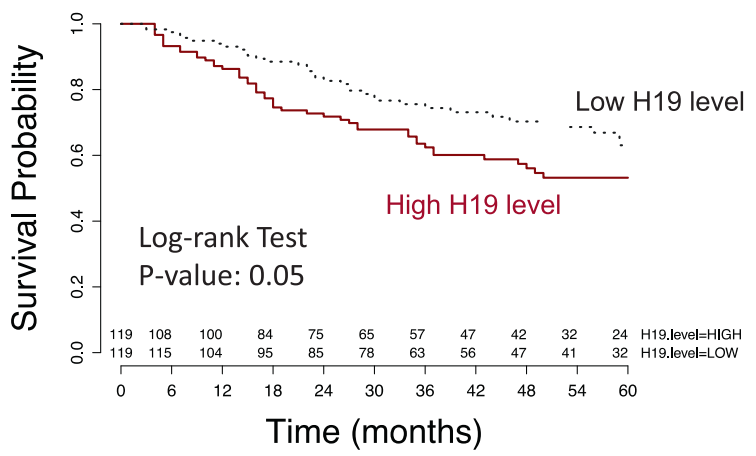

background. We demonstrate, using smRNA-FISH technology, that in old $M d r 2-K O$ mice of the C57BL/6 genetic background, $H 19$ is expressed mainly in hepatocytes, with minor expression in endothelial cells and monocytes/macrophages/Kupffer cells. Thus, our results are in agreement with the results of L. Wang's group.

\section{Liver injury and H19}

Our previous finding of increased $H 19$ expression in the nontumor liver of adult $M d r 2-K O$ mice [9] is in line with the published observations of the same effect in cirrhotic liver of mice and patients [22-24]. Remarkably, H19 knockdown significantly reduced liver injury in two different models of cholestatic injury: mice with hepatic overexpression of Bcl2 [24] and $M d r 2-K O$ mice [17]. In both these studies, increased $H 19$ expression was accompanied by downregulation of the NrOb2/Shp expression. We also demonstrate increased expression of genes associated with inflammation and epithelial-tomesenchymal transition in $M d r 2-K O$ versus $d K O$ females, as well as a reverse correlation between $\mathrm{H} 19$ and $\mathrm{NrOb} 2$ expression (Fig. 5). This difference was more prominent at the young age, when $M d r 2-K O$ females had increased serum ALT and ALP levels and increased LBI versus $d K O$ females (Fig. 3A, B). Recently, it was demonstrated that B cells infiltrating the liver of $M d r 2-K O$ mice promote liver fibrosis and pro-tumorigenic $\mathrm{TNF} \alpha / \mathrm{NF}-\mathrm{\kappa B}$ signaling [25]. We found reduced B cells infiltration into the liver of young $d K O$ versus $M d r 2-K O$ females (Fig. 3D, E), which was associated with significant downregulation of Ccl21a (Fig. 5B), a chemoattractor of B cells [26]. We hypothesize that downregulation of $C c l 21 a$ and concomitant reduced $\mathrm{B}$ cells infiltration into the livers of young $d K O$ mice may 
contribute to the retardation of hepatocarcinogenesis in dKO mice.

It should be mentioned that, although dKO livers were at average 4\% smaller than Mdr2-KO livers of 3-month-old females, both groups had comparable numbers of hepatocytes due to a reduced proportion of cholangiocytes in $\mathrm{dKO}$ females, thus ruling out the possibility that the difference in hepatocarcinogenesis between groups could be explained by differences in hepatocyte numbers in their livers.

\section{Hepatocyte polyploidy and H19}

Induction of $H 19$ expression in the injured liver could be associated with its yet undetermined role in hepatocyte proliferation. Increased expression of $H 19$ (but not Igf2) in post-hepatectomized rodent liver was shown to be preceded by peaks of DNA synthesis and PCNA expression [11]. Previously, we have demonstrated that $M d r 2-K O$ mutation in the FVB/N strain caused a significantly reduced number of binuclear hepatocytes at both early and late ages [27]. Now, we have found that young B6 Mdr2-KO females contain significantly less binuclear hepatocytes in the liver compared to $d K O$ females (Fig. 4A, B). Thus, H19 loss partially compensates for the reduction of the fraction of binuclear hepatocytes in the liver of $M d r 2-K O$ mice. Hepatocyte binuclearity is one of the forms of hepatocyte polyploidy, and binuclear hepatocytes represent the main fraction of polyploid hepatocytes in the rodent liver [14]. Importantly, our finding of increased proportion of binuclear hepatocytes in the absence of H19 is in accordance with the previously published data that $H 19$ expression in primary hepatocytes was reversely correlated with cell polyploidization [13]. Remarkably, polyploid state of hepatocytes plays a tumor-suppressive role in the murine liver [28, 29]. These findings suggest that reduction of hepatocytes' polyploidy by H19 may be one of the mechanisms responsible for the pro-oncogenic effect of $H 19$ in the Mdr2-KO HCC model.

\section{Transcriptomic analysis}

Transcriptomic analysis of differentially expressed genes (DEGs) in the liver of $d K O$ versus $M d r 2-K O$ females, revealed less intensive inflammatory response and epithelial-mesenchymal transition in $d K O$ mice at both young and old ages (Fig. 5A). This difference was more prominent at the young age, in agreement with the significantly reduced liver injury (reflected by reduced serum ALT and ALP activities) in the young $d K O$ females. Analysis of specific DEGs provides clues to the molecular mechanisms causing retardation of HCC development in Mdr2-KO mice deficient in H19. Among DEGs in the young females that we validated by qRT-PCR, genes
S100a8, S100a9, Ly6c1, and Orm2 were significantly upregulated in the $M d r 2-K O$ versus $d K O$ females (Fig. 5B), and genes Saal, Saa2, Cxcll, and Lcn2 had a tendency to be upregulatied in $M d r 2-K O$ females (data not shown). Remarkably, it has been recently shown that upregulation of all genes mentioned above in the mouse liver is a part of the "intercellular network underpinned by hepatocytes that forms the basis of a pro-metastatic niche in the liver" [30]. Thus, less efficient formation of the pro-metastatic niches in the liver of young $d K O$ mice could contribute to molecular mechanisms that determine reduced HCC development in the absence of H19. The pro-tumorigenic function of the S100A8 and S100A9 genes in inflammation-mediated hepatocarcinogenesis has been previously demonstrated [31]. Interestingly, we found that $\mathrm{H} 19$ loss in $\mathrm{Mdr2}-\mathrm{KO}$ females was accompanied by increased expression of the $T s c 22 d 3$ gene encoding potent anti-inflammatory protein Gilz, which inhibits activation of different types of immune cells: macrophages [32], neutrophils [33], and B cells [34]. Upregulation of the $T$ cim/C8orf4 expression in $d K O$ versus $M d r 2-K O$ liver also could have a tumor-suppressive effect, since Tcim/C8orf4 suppresses self-renewal of liver cancer stem cells [35].

Other DEGs upregulated upon $H 19$ loss in young mice are involved in the regulation of lipids' (Foxol) or bile acids' (NrOb2/Shp) metabolism. A negative correlation between expression levels of $\mathrm{H} 19$ and either Foxol [36], or NrOb2/Shp [37] in the murine liver has been demonstrated previously; thus, our data corroborate these findings. Transcription factor Foxo1 may promote the antitumor activity of tumorassociated macrophages [38] and has a tumor-suppressive activity in HCC [39, 40]. Both Duspl and Gadd45g genes, that were confirmed to be upregulated in the liver of old $d K O$ versus $M d r 2-K O$ females, have tumor-suppressive activities [41-43]. Duspl is also a key mediator in the glucocorticoiddriven anti-inflammatory responses [44].

H19 encodes highly conserved miR-675-5p and miR$675-3 p$, both targeting multiple cellular genes $[2,16]$. We detected low levels of both miR-675 variants in the livers of the 15-day-old mice that highly express H19: miR-675-5p -at the level $0.05-0.1 \%$ of the RNU6 level and miR-675$3 \mathrm{p}$ - at the level $0.2-0.25 \%$ of the RNU6 level (data not shown). However, in the nontumor liver of 16-month-old females, miR-675-5p was hardly detectable, while miR$675-3 p$ was detected at the level $0.01-0.02 \%$ of the RNU6 level (data not shown). Importantly, there was no correlation between expression levels of miR-675-3p and H19 in the murine liver, and none of the known (and suggested by TargetScan) targets of both these miRNAs was upregulated in the liver of H19-KO mice tested by RNA-seq. Thus, our data do not provide evidence for a functional role of the miR-675 variants in the H19-dependent phenotypes observed in the B6 Mdr2-KO mice. 


\section{H19 level in HCC and patients' survival}

Our measurements of the $H 19$ level in nontumor liver tissue of HCC patients corroborated our finding in the $M d r 2-K O$ mice: increased $H 19$ expression in cirrhosis and fibrosis, and higher $H 19$ level in females versus males (Fig. 6); the latter tendency took place also in HCC tumors (Fig. 7C). Most human tumors had low or very low levels of H19 expression compared to their matched nontumor counterparts; tumors with high $\mathrm{H} 19$ expression were present mainly in the "proliferative" class G1 (Fig. 7A). There was a strong negative correlation between $\mathrm{H} 19$ expression level and presence of CTNNB1 mutations in HCC tumors (Fig. 7D). Similar observations of $\mathrm{H} 19$ overexpression in the "proliferative class" of tumors, which is characterized by a very low number of CTNNB1 mutations, were made previously on another dataset of HCC tumors [45]. We found that level of $\mathrm{H} 19$ expression in tumors inversely affected patient's survival in our HCC dataset (Fig. 7E and Supplementary Table 5), but not in the TCGA dataset (Supplementary Fig. 5). Nevertheless, other studies demonstrated that disease-free survival of HCC patients inversely correlated with $H 19$ level in tumors [46] and that low tumor/nontumor ration of $H 19$ was associated with poor prognosis [47].

Altogether, our results point to several possible molecular mechanisms responsible for the reduced HCC development in $d K O$ mice. This is in accordance with the known multiple activities of $H 19$ lncRNA, which interacts and interferes with functions of multiple proteins and microRNAs [16]. $H 19$ is not a classical oncogene because it is not expressed (or scantly expressed) in most human and murine HCC tumors. Our data suggest that the pro-carcinogenic activity of $H 19$ in $\mathrm{HCC}$ development is manifested mainly by formation of a pro-tumorigenic microenvironment, and decreased hepatocytes' polyploidy in young animals as well as increased hepatocyte proliferation at all ages (Fig. 8). We have identified several genes that could be responsible for the anti-inflammatory and tumor-suppressive effects of $H 19$ loss in the liver of $M d r 2-K O$ mice at both young and old ages. The results of single-cell transcriptomics show that H19 is expressed mainly in hepatocytes, endothelial cells, and macrophages/monocytes. Further studies are necessary in order to reveal the exact molecular effects of $H 19$ expression in each mentioned liver cell type.

\section{Materials and methods}

\section{Mice}

All animal experiments were performed according to national regulations and guidelines of the Institutional Animal Welfare Committee (NIH approval number OPRR-

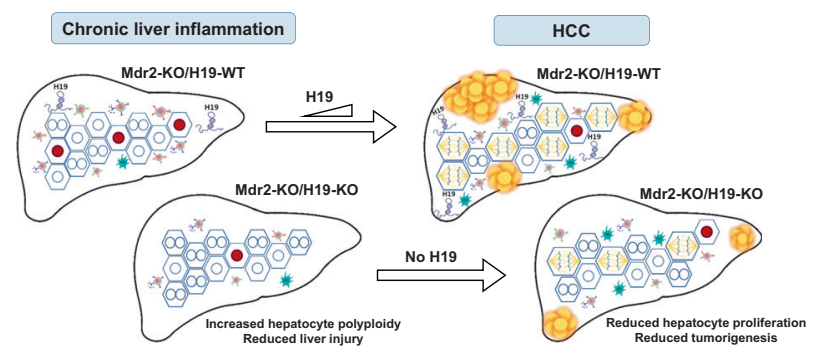

Fig. 8 In the $M d r 2-K O$ model of chronic inflammation-mediated HCC, H19 has a pro-oncogenic role. H19 expression is highly variable in the nontumor liver of the aged $\mathrm{B} 6 \mathrm{Mdr2}-\mathrm{KO}$ females, and is very low or absent in their tumors. In the nontumor liver of very young and of aged B6 Mdr2-KO females, H19 is expressed mainly in hepatocytes; in the aged females, it is expressed also in endothelial cells and in monocytes/macrophages. The pro-carcinogenic effect of $H 19$ expression in the liver is manifested mainly by increased liver injury, increased hepatocyte proliferation, decreased hepatocyte ploidy, and by formation of the pro-tumorigenic microenvironment, starting from the early stages of the disease.

A01-5011). The H1943 mutant of the 129SV strain was kindly provided by Prof. Luisa Dandolo (Inserm U1016, Institute Cochin, Paris, France). The C57BL/6 Abcb4 $4^{\mathrm{tm} 1 \mathrm{Bor}}$ (B6 Mdr2-KO) and B6 Mdr2-KO/H19-KO (dKO) mice were produced in our institute as described in Supplementary Methods. In order to investigate the role of $H 19$ in liver tumor development, females of both B6 Mdr2-KO and $d K O$ genotypes were terminated for tumor counting and liver tissue collection at the age of 16 months. Due to delayed HCC development in the B6 Mdr2-KO males versus females, male mice were terminated at the age of 17.5 months.

\section{Gene expression analyses}

Total RNA was isolated from frozen liver tissues using Trizol reagent (Invitrogen, Carlsbad, CA) as described by the manufacturer, following by DNaseI treatment using the DNaseI kit (Invitrogen, Vilnius, Lithuania), or using the miRNeasy kit (Qiagen, Hiden, Germany). Quantitative realtime RT-PCR was performed using the qScript cDNA Synthesis kit and qPCR SYBR Green fast mix PCR kit (both kits of QuantaBio, Beverly, MA) using primers shown in Supplementary Table 6. Reactions were run on a CFX384 ${ }^{\mathrm{TM}}$ Real-Time System with C1000 Touch Thermal Cycle (BioRad, Hercules, CA, USA). RNA-seq analysis was conducted by the Technion Genome Center of the Israeli Institute of Technology ("Technion", Haifa, Israel). Single-cell RNA-seq analysis was conducted by the Core Research Facility at The Faculty of Medicine, Ein Kerem, The Hebrew University and by the Bioinformatics Unit of the I-CORE Computation Center at The Hebrew University and Hadassah (Jerusalem, Israel). 


\section{Immunoblotting and immunohistochemistry/ immunofluorescence}

Protein detection was performed by immunoblotting of proteins that were electro-transferred from 2-D gel to PVDF membrane, and by IHC/immunofluorescence staining of formalin-fixed paraffin-embedded liver tissue sections as described [7, 9], using antibodies shown in Supplementary Table 7.

\section{Statistical analysis}

Statistical significance between groups was estimated using either the Fisher exact two-tailed test (for tumor incidence), or the two-tailed unpaired $t$-test (in all other cases, excluding RNA-seq analysis). Results are expressed as the mean \pm standard deviation; differences were considered significant at $p<0.05$. For human samples, comparison of a continuous variable in two and more groups was performed using the Wilcoxon signed-rank test and Kruskal-Wallis test, respectively. Correlation analysis between continuous variables was performed using Spearman's rank-order correlation. Survival analysis was performed using the Kaplan-Meier curve with log-rank test (univariate) and by Cox regression analysis (univariate and multivariate).

Full details and other methods are available in the Supplementary Materials and Methods.

Acknowledgements The authors thank Sharona Elgavish, Yuval Nevo, and Hadar Benyamini (Bioinformatics Unit of the I-CORE Computation Center at The Hebrew University and Hadassah, Jerusalem, Israel) for single-cell transcriptomic (SE \& YN) and gene set enrichment (HB) analyses, Zakharia Manevich (The Core Research Facility at The Faculty of Medicine, Ein Kerem, The Hebrew University, Jerusalem, Israel) for advice with confocal microscopy, Luisa Dandolo (Institut Cochin, Paris, France) for providing the 129Sv H1943 mutant mice, Shalev Itzkovitz (Weizmann Institute of Science, Rehovot, Israel) for useful discussions and help with smRNA-FISH, Ilan Stein and Yoganathan Krishnamoorthy (Department of Pathology, Hebrew University-Hadassah Medical School) for advice with immunohistochemistry, and Hilla Giladi (The Goldyne Savad Institute of Gene Therapy) for critical reading of the manuscript.

Funding Robert H. Benson Living Trust and Selma Kron Foundation to student fellowships. DSG is supported by the Kamea Scientific Foundation of the Israeli Government. JHA was supported by ISF 923/ 14. SC was supported by a funding from Labex OncoImunology and CARPEM. The JZR group was supported by INSERM, Ligue Nationale contre le Cancer (Equipe Labellisée), Labex OncoImmunology (investissement d'avenir), grant IREB, Coup d'Elan de la Fondation Bettencourt-Schueller, the SIRIC CARPEM, Raymond Rosen Award from the Fondation pour le Recherche Médicale, Prix René and Andrée Duquesne-Comité de Paris Ligue Contre le Cancer and Fondation Mérieux. The work of EG was supported by the: ERC advance-GA No. 786575-RxmiRcanceR, Deutsche Forschungsgemeinschaft (DFG) SFB841 project C3, NIH CA197081-02, MOST, ISF collaboration with Canada (2473/2017), personal ISF (486/2017), ICORE-ISF (41/2011), and by DKFZ-MOST.
Author contributions LG and LM: main part of the experimental work and discussions; TF and EZ: data acquisition; NR: data acquisition (single-cell analysis); OP: data analysis (pathology); DO: assistance with mice and liver samples processing; $\mathrm{KBH}$ : help with smRNAFISH and discussions; SC and JZ-R: human HCC data analysis and discussions; JHA: help with mice, discussions, manuscript editing; EG: study idea and discussions, manuscript editing; DSG: study design, data acquisition and analysis, manuscript writing, and discussions.

\section{Compliance with ethical standards}

Conflict of interest The authors declare that they have no conflict of interest.

Publisher's note Springer Nature remains neutral with regard to jurisdictional claims in published maps and institutional affiliations.

\section{References}

1. Llovet JM, Zucman-Rossi J, Pikarsky E, Sangro B, Schwartz M, Sherman M, et al. Hepatocellular carcinoma. Nat Rev Dis Prim. 2016;2:16018.

2. Raveh E, Matouk IJ, Gilon M, Hochberg A. The H19 long noncoding RNA in cancer initiation, progression and metastasis-a proposed unifying theory. Mol Cancer. 2015;14:184.

3. Yoshimizu T, Miroglio A, Ripoche MA, Gabory A, Vernucci M, Riccio A, et al. The H19 locus acts in vivo as a tumor suppressor. Proc Natl Acad Sci USA. 2008;105:12417-22.

4. Matouk IJ, DeGroot N, Mezan S, Ayesh S, Abu-lail R, Hochberg A, et al. The H19 non-coding RNA is essential for human tumor growth. PLoS ONE. 2007;2:e845.

5. Mauad TH, van Nieuwkerk CM, Dingemans KP, Smit JJ, Schinkel AH, Notenboom RG, et al. Mice with homozygous disruption of the mdr2 P-glycoprotein gene. A novel animal model for studies of nonsuppurative inflammatory cholangitis and hepatocarcinogenesis. Am J Pathol. 1994;145:1237-45.

6. Katzenellenbogen M, Pappo O, Barash H, Klopstock N, Mizrahi L, Olam D, et al. Multiple adaptive mechanisms to chronic liver disease revealed at early stages of liver carcinogenesis in the Mdr2-knockout mice. Cancer Res. 2006;66:4001-10.

7. Katzenellenbogen M, Mizrahi L, Pappo O, Klopstock N, Olam D, Jacob-Hirsch J, et al. Molecular mechanisms of liver carcinogenesis in the Mdr2-knockout mice. Mol Cancer Res. 2007;5:1159-70.

8. Potikha T, Stoyanov E, Pappo O, Frolov A, Mizrahi L, Olam D, et al. Interstrain differences in chronic hepatitis and tumor development in a murine model of inflammation-mediated hepatocarcinogenesis. Hepatology. 2013;58:192-204.

9. Ella E, Heim D, Stoyanov E, Harari-Steinfeld R, Steinfeld I, Pappo O, et al. Specific genomic and transcriptomic aberrations in tumors induced by partial hepatectomy of a chronically inflamed murine liver. Oncotarget. 2014;5:10318-31.

10. Martinez-Quetglas I, Pinyol R, Dauch D, Torrecilla S, Tovar V, Moeini A, et al. IGF2 Is up-regulated by epigenetic mechanisms in hepatocellular carcinomas and is an actionable oncogene product in experimental models. Gastroenterology. 2016;151:1192-205.

11. Yamamoto Y, Nishikawa Y, Tokairin T, Omori Y, Enomoto K. Increased expression of $\mathrm{H} 19$ non-coding mRNA follows hepatocyte proliferation in the rat and mouse. J Hepatol. 2004;40:808-14.

12. Pope C, Piekos SC, Chen L, Mishra S, Zhong XB. The role of H19, a long non-coding RNA, in mouse liver postnatal maturation. PLoS ONE. 2017;12:e0187557.

13. Shoshani O, Massalha H, Shani N, Kagan S, Ravid O, Madar S, et al. Polyploidization of murine mesenchymal cells is associated 
with suppression of the long noncoding RNA H19 and reduced tumorigenicity. Cancer Res. 2012;72:6403-13.

14. Guidotti JE, Bregerie O, Robert A, Debey P, Brechot C, Desdouets C. Liver cell polyploidization: a pivotal role for binuclear hepatocytes. J Biol Chem. 2003;278:19095-101.

15. Boyault S, Rickman DS, de Reynies A, Balabaud C, Rebouissou $\mathrm{S}$, Jeannot E, et al. Transcriptome classification of HCC is related to gene alterations and to new therapeutic targets. Hepatology. 2007;45:42-52.

16. Lecerf $\mathrm{C}$, Le Bourhis $\mathrm{X}$, Adriaenssens E. The long non-coding RNA H19: an active player with multiple facets to sustain the hallmarks of cancer. Cell Mol Life Sci. 2019;76:4673-87.

17. Li X, Liu R, Yang J, Sun L, Zhang L, Jiang Z, et al. The role of long noncoding RNA H19 in gender disparity of cholestatic liver injury in multidrug resistance 2 gene knockout mice. Hepatology. 2017;66:869-84.

18. Adriaenssens E, Lottin S, Dugimont T, Fauquette W, Coll J, Dupouy JP, et al. Steroid hormones modulate $\mathrm{H} 19$ gene expression in both mammary gland and uterus. Oncogene. 1999;18:4460-73.

19. Yang F, Bi J, Xue X, Zheng L, Zhi K, Hua J, et al. Up-regulated long non-coding RNA H19 contributes to proliferation of gastric cancer cells. FEBS J. 2012;279:3159-65.

20. Schultheiss CS, Laggai S, Czepukojc B, Hussein UK, List M, Barghash A, et al. The long non-coding RNA H19 suppresses carcinogenesis and chemoresistance in hepatocellular carcinoma. Cell Stress. 2017;1:37-54.

21. Jiang Y, Huang Y, Cai S, Song Y, Boyer JL, Zhang K, et al. H19 is expressed in hybrid hepatocyte nuclear factor 4alpha $(+)$ periportal hepatocytes but not cytokeratin $19(+)$ cholangiocytes in cholestatic livers. Hepatol Commun. 2018;2:1356-68.

22. Chen X, Yamamoto M, Fujii K, Nagahama Y, Ooshio T, Xin B, et al. Differential reactivation of fetal/neonatal genes in mouse liver tumors induced in cirrhotic and non-cirrhotic conditions. Cancer Sci. 2015;106:972-81.

23. Uehara T, Ainslie GR, Kutanzi K, Pogribny IP, Muskhelishvili L, Izawa $\mathrm{T}$, et al. Molecular mechanisms of fibrosis-associated promotion of liver carcinogenesis. Toxicol Sci. 2013;132:53-63.

24. Zhang Y, Liu C, Barbier O, Smalling R, Tsuchiya H, Lee S, et al. $\mathrm{Bcl} 2$ is a critical regulator of bile acid homeostasis by dictating Shp and lncRNA H19 function. Sci Rep. 2016;6:20559.

25. Faggioli F, Palagano E, Di Tommaso L, Donadon M, Marrella V, Recordati C, et al. B lymphocytes limit senescence-driven fibrosis resolution and favor hepatocarcinogenesis in mouse liver injury. Hepatology. 2018;67:1970-85.

26. Zhao R, Chen X, Ma W, Zhang J, Guo J, Zhong X, et al. A GPR174-CCL21 module imparts sexual dimorphism to humoral immunity. Nature. 2020;577:416-20.

27. Stoyanov E, Ludwig G, Mizrahi L, Olam D, Schnitzer-Perlman T, Tasika E, et al. Chronic liver inflammation modifies DNA methylation at the precancerous stage of murine hepatocarcinogenesis. Oncotarget. 2015;6:11047-60.

28. Zhang S, Zhou K, Luo X, Li L, Tu HC, Sehgal A, et al. The polyploid state plays a tumor-suppressive role in the liver. Dev Cell. 2018;44:447-59.e5.

29. Wilkinson PD, Delgado ER, Alencastro F, Leek MP, Roy N, Weirich MP, et al. The polyploid state restricts hepatocyte proliferation and liver regeneration in mice. Hepatology. 2019;69:1242-58.

30. Lee JW, Stone ML, Porrett PM, Thomas SK, Komar CA, Li JH, et al. Hepatocytes direct the formation of a pro-metastatic niche in the liver. Nature. 2019;567:249-52.

31. Nemeth J, Stein I, Haag D, Riehl A, Longerich T, Horwitz E, et al. S100A8 and S100A9 are novel nuclear factor kappa B target genes during malignant progression of murine and human liver carcinogenesis. Hepatology. 2009;50:1251-62.

32. Robert O, Boujedidi H, Bigorgne A, Ferrere G, Voican CS, Vettorazzi S, et al. Decreased expression of the glucocorticoid receptor-GILZ pathway in Kupffer cells promotes liver inflammation in obese mice. J Hepatol. 2016;64:916-24.

33. Ricci E, Ronchetti S, Gabrielli E, Pericolini E, Gentili M, Roselletti E, et al. GILZ restrains neutrophil activation by inhibiting the MAPK pathway. J Leukoc Biol. 2019;105:187-94.

34. Jones SA, Toh AE, Odobasic D, Oudin MA, Cheng Q, Lee JP, et al. Glucocorticoid-induced leucine zipper (GILZ) inhibits B cell activation in systemic lupus erythematosus. Ann Rheum Dis. 2016;75:739-47.

35. Zhu P, Wang Y, Du Y, He L, Huang G, Zhang G, et al. C8orf4 negatively regulates self-renewal of liver cancer stem cells via suppression of NOTCH2 signalling. Nat Commun. 2015;6:7122.

36. Goyal N, Tiwary S, Kesharwani D, Datta M. Long non-coding RNA H19 inhibition promotes hyperglycemia in mice by upregulating hepatic FoxO1 levels and promoting gluconeogenesis. J Mol Med. 2019;97:115-26.

37. Li X, Liu R, Huang Z, Gurley EC, Wang X, Wang J, et al. Cholangiocyte-derived exosomal long noncoding RNA H19 promotes cholestatic liver injury in mouse and humans. Hepatology. 2018;68:599-615.

38. Yang JB, Zhao ZB, Liu QZ, Hu TD, Long J, Yan K, et al. FoxO1 is a regulator of MHC-II expression and anti-tumor effect of tumor-associated macrophages. Oncogene. 2018;37:1192-204.

39. Yang XW, Shen GZ, Cao LQ, Jiang XF, Peng HP, Shen G, et al. MicroRNA-1269 promotes proliferation in human hepatocellular carcinoma via downregulation of FOXO1. BMC Cancer. 2014;14:909.

40. Yang N, Zhou J, Li Q, Han F, Yu Z. miR-96 exerts carcinogenic effect by activating AKT/GSK-3beta/beta-catenin signaling pathway through targeting inhibition of FOXO1 in hepatocellular carcinoma. Cancer Cell Int. 2019;19:38.

41. Hao PP, Li H, Lee MJ, Wang YP, Kim JH, Yu GR, et al. Disruption of a regulatory loop between DUSP1 and p53 contributes to hepatocellular carcinoma development and progression. J Hepatol. 2015;62:1278-86.

42. Ying J, Srivastava G, Hsieh WS, Gao Z, Murray P, Liao SK, et al. The stress-responsive gene GADD45G is a functional tumor suppressor, with its response to environmental stresses frequently disrupted epigenetically in multiple tumors. Clin Cancer Res. 2005;11:6442-9.

43. Xu G, Zhang L, Ma A, Qian Y, Ding Q, Liu Y, et al. SIP1 is a downstream effector of GADD45G in senescence induction and growth inhibition of liver tumor cells. Oncotarget. 2015;6: 33636-47.

44. Hoppstadter J, Ammit AJ. Role of dual-specificity phosphatase 1 in glucocorticoid-driven anti-inflammatory responses. Front Immunol. 2019;10:1446.

45. Chiang DY, Villanueva A, Hoshida Y, Peix J, Newell P, Minguez B, et al. Focal gains of VEGFA and molecular classification of hepatocellular carcinoma. Cancer Res. 2008;68:6779-88.

46. Zhang J, Han C, Ungerleider N, Chen W, Song K, Wang Y, et al. A transforming growth factor-beta and H19 signaling axis in tumor-initiating hepatocytes that regulates hepatic carcinogenesis. Hepatology. 2019;69:1549-63.

47. Zhang L, Yang F, Yuan JH, Yuan SX, Zhou WP, Huo XS, et al. Epigenetic activation of the MiR-200 family contributes to H19mediated metastasis suppression in hepatocellular carcinoma. Carcinogenesis. 2013;34:577-86. 